\title{
A Case Report of Imatinib-induced Acute Heart Failure and Literature Review
}

\author{
Zhaodong $\mathrm{Li}^{1}$, Wen $\mathrm{Qu}^{2}$, Xiaolin $\mathrm{He}^{3}$, Xinhua Zhao ${ }^{1}$, Yujun $\mathrm{Luo}^{1}$ and Jinhong Wang ${ }^{4}$ \\ ${ }^{1}$ Department of Gastroenterology, Mianyang Central Hospital, Jingzhong Road, Fucheng District, Mianyang City, Sichuang, China \\ ${ }^{2}$ Department of Hematopathology, Mianyang Central Hospital, Fucheng District, Mianyang City, Sichuang, China \\ ${ }^{3}$ Department of Obstetrics and Gynecology, The People's Hospital of Anzhou County, Anzhou District, Mianyang City, Sichuan, China \\ ${ }^{4}$ Department of Ultrasonography, Mianyang Central Hospital, Fucheng District, Mianyang City, Sichuang, China
}

\begin{abstract}
Patients with Philadelphia chromosome-positive $(\mathrm{Ph}+)$ chronic myeloid leukemia (CML), gastrointestinal stromal tumors (GISTs) or acute lymphoblastic leukemia (ALL) are appropriate candidates for medical treatment using imatinib. Here, we report a case of imatinib-induced acute heart failure in a patient with ALL and retrospectively analyse the adverse reactions of imatinib. The patient was a 45-year man with $\mathrm{Ph}+$ and bcr-abl positive (bcr-abl+) ALL. He was treated with imatinib approximately four months ago. At that time, he had no risk factors for cardiac disease, and his heart function was normal. Then, four months after starting imatinib, he manifested signs of acute heart failure. A retrospective analysis of the adverse reactions in 100 cases of leukemia patients, who took imatinib in the past three years, indicated a rare incidence of congestive heart failure among those patients. Our experience in treating the patient suggests that brain natriuretic peptide levels and cardiac doppler examinations should be monitored closely in these patients.
\end{abstract}

Key Words: Imatinib, Acute lymphoid leukemia, Acute heart failure.

How to cite this article: Li Z, Qu W, He X, Zhao X, Luo Y, Wang J. A Case Report of Imatinib-induced Acute Heart Failure and Literature Review. J Coll Physicians Surg Pak 2022; 32(01):114-116.

\section{INTRODUCTION}

Imatinib mesylate is a type of oral tyrosine kinase inhibitor (TKI) that isused in the treatment of Philadelphia chromosome-positive $(\mathrm{Ph}+)$ blood malignant cancers, such as $\mathrm{Ph}+\mathrm{CML}, \mathrm{Ph}+\mathrm{ALL}$, and malignant gastrointestinal stromal tumors (GISTs). ${ }^{1}$ Imatinib may cause neutropenia, thrombocytopenia, anemia, edema, etc. ${ }^{2}$ Some experts have also reported that the use of imatinib is associated with the risk of congestive heart failure. ${ }^{3,4}$ However, there has never been a report of imatinib-induced heart failure from China. We report a case of imatinib-induced acute heart failure and fatal thrombocytopenia; and review the adverse reactions in 100 cases of leukemia patients taking imatinib in the pastthree years.

\section{CASE REPORT}

A 45-year male patient presented with confirmed ALL for four months and fatigue for 10 days, to the Department of Hematopathology of our hospital on March $7^{\text {th }}, 2019$.

Correspondence to: Jinhong Wang, Department of Ultrasonography, Mianyang Central Hospital, Jingzhong Road, Fucheng District, Mianyang City, Sichuang, China

E-mail: jinhongwangus@163.com

Received: February 25, 2020; Revised: September 08, 2020;

Accepted: October 18, 2020

DOI: https://doi.org/10.29271/jcpsp.2022.01.114
He was diagnosed as ALL-(BCR/ABL+) by bone marrow biopsy, karyotyping and fusion gene analysis; and treated with imatinib four months ago. Prior to receiving imatinib treatment, the patient had no history of cardiovascular disease, and his heart function was normal. After receiving imatinib, he experienced some relief. Ten days later, he felt progressive aggravation of fatigue and gradually anasarca appeared, which was more apparent in the legs, as well as insomnia, shortness of breath, and poor appetite, without fever, nausea and vomiting .

On physical examination, he was conscious, but had edema, moderate anemia, and both limbs showed visible and scattered petechiae. Bilateral breath sounds were audible but unclear, scattered and wet; there was no pleural rub. The heart rate was 120 times/min with sinus rhythm, but valvular insufficiency murmur. The laboratory tests revealed white blood cells to be $211 \times 10^{9} / \mathrm{L}$, hemoglobin $80 \mathrm{~g} / \mathrm{L}$, and platelets $2 \times 10^{9} / \mathrm{L}$. Liver functions showed ALT of $100 \mathrm{U} / \mathrm{L}$ and AST $120 \mathrm{U} / \mathrm{L}$. Serum LDH-L was $151 \mathrm{U} / \mathrm{L}$, proBNP $2000 \mathrm{ng} / \mathrm{L}$, PCT $1.1 \mu \mathrm{g} / \mathrm{L}$, e CRP 117.36 $\mathrm{mg} / \mathrm{L}$, and CK-MB $3.32 \mathrm{ng} / \mathrm{ml}$.

We treated the patient concurrently with large-volume leukapheresis, liver protectant, diuresis, anti-infection and one dose of platelets. After three days, the patient's condition worsened. He experienced severe dyspnea and his heart showed signs of exhaustion after slight activity. The cardiac Doppler revealed the ejection fraction to be $28 \%$; he had generalised cardiomegaly, severe tricuspid regurgitation, and moderate mitral valve regurgitation. But, before the patient received the imatinib 
treatment, his atria and ventricles were normal, and the interventricular septum and the posterior wall of the left ventricle were normal in thickness and amplitude (Figure 1). Immediately, we stopped imatinib treatment and gave the patient diuretics and cardiac medications. The patient's symptoms were relieved, but he died of cerebral hemorrhage, caused by thrombocytopenia after two days.

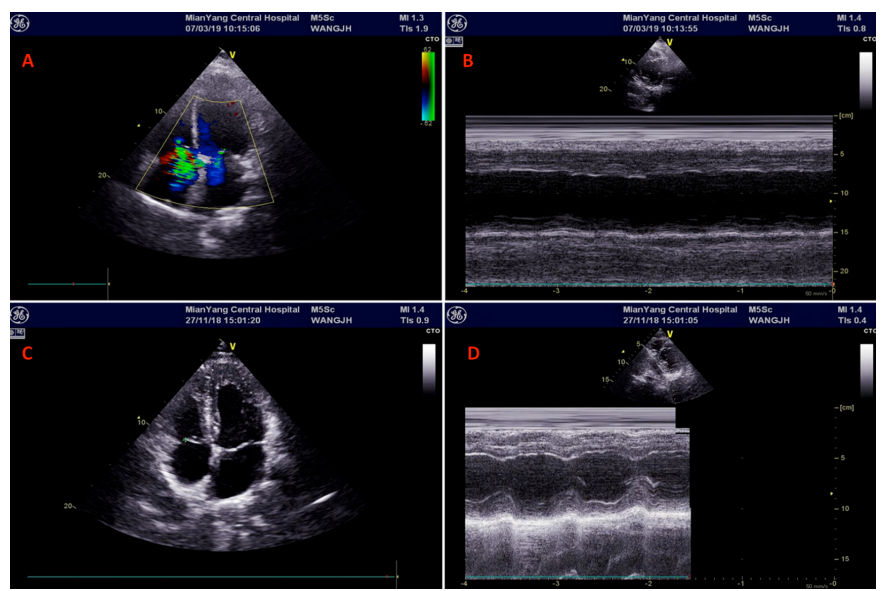

Figure 1: (A, B) The patient's heart was enlarged, the valvular regurgitation was severe, the ventricular wall thinner, and flexibility decreased after imatinib use. The anterior and posterior diameter of the left ventricle was $61 \mathrm{~mm}$, the thickness of the left ventricular wall was $5 \mathbf{~ m m}$, and the ejection fraction was $28 \%$. (C, D) The atria and ventricles were normal, and the interventricular septum and the posterior wall of the left ventricle were normal in thickness and amplitude before imatinib use. The anterior and posterior diameter of the left ventricle was $46 \mathrm{~mm}$, the thickness of the left ventricular wall was $9 \mathrm{~mm}$, and the ejection fraction was $62 \%$.

Imatinib-induced heart failure is rare, and we retrospectively reviewed the adverse reactions of 100 leukemia patients with imatinib treatment in the past three years. The results showed that the main adverse reactions to imatinib occurred in the blood system, such as leukopenia, erythropenia and thrombocytopenia. Non-hematological adverse reactions included edema, water and sodium retention, digestive symptoms, muscle aches and cramps, and abnormal liver and kidney function (Table I). The condition of almost all those patients were not serious and the adverse reactions were tolerable.

Table I: Organs and systems involved in the adverse reactions to imatinib.

\begin{tabular}{|c|c|c|c|}
\hline $\begin{array}{l}\text { Organs and } \\
\text { systems }\end{array}$ & $\mathbf{n}$ & $\begin{array}{c}\text { Composition } \\
\text { ratio (\%) }\end{array}$ & Clinical manifestations \\
\hline Blood & 65 & $65 \%$ & $\begin{array}{l}\text { Reduction in white blood } \\
\text { cells, hemoglobin, and } \\
\text { platelets }\end{array}$ \\
\hline Liver and kidney & 13 & $13 \%$ & $\begin{array}{l}\text { Elevated transaminases, } \\
\text { bilirubin, creatinine, and uric } \\
\text { acid }\end{array}$ \\
\hline Digestive system & 33 & $33 \%$ & $\begin{array}{l}\text { Nausea, constipation, } \\
\text { diarrhea }\end{array}$ \\
\hline Skin & 9 & $9 \%$ & $\begin{array}{l}\text { Multiple serous effusions, skin } \\
\text { edema }\end{array}$ \\
\hline Circulatory system & 0 & 0 & $\begin{array}{l}\text { Palpitations, irregular } \\
\text { heartbeat, heart failure }\end{array}$ \\
\hline Muscle & 30 & $30 \%$ & Muscle soreness and cramps \\
\hline Other & 15 & $15 \%$ & $\begin{array}{l}\text { Fatigue, poor appetite, } \\
\text { insomnia }\end{array}$ \\
\hline
\end{tabular}

\section{DISCUSSION}

Imatinib inhibits the fusion protein product of the fusion gene $B C R / A B L$, which is formed by reciprocal translocation of $A B L$ proto-oncogene on chromosome 9 with BCR gene on chromosome 22 of human cells. Imatinib, in particular, inhibits the active binding site for adenosine triphosphate (ATP) on the fusion protein; thus, inhibiting the phosphorylation of the abl tyrosine kinase. This, in turn, inhibits the cell proliferation and increases apoptosis. ${ }^{1}$ This patient had the fusion gene $B C R / A B L$, which conformed to the use of imatinib chemotherapy. The preclinical findings suggest that imatinib remains a potential cardiotoxin. Trent et al. recommend treating the risk factors for cardiovascular disease in imatinib-treated patients in accordance with the American Heart Association ( $\mathrm{AHA}$ ) guidelines for the prevention and treatment of heart failure. ${ }^{5}$

Cardiac toxicity can be caused by the tyrosine kinase inhibitors, like imatinib mesylate, dasatinib, nilotinib, sunitinib, sorafenib and lapatinib. The cardiotoxic events may range from asymptomatic subclinical abnormalities such as electrocardiographic changes and left ventricular ejection fraction decline to lifethreatening events, such as congestive heart failure and acute coronarysyndromes. ${ }^{6}$ The mechanisms behind toxiccardiomyopathy are complex and multifactorial, but include interference with the myocardial cell bioenergetics and intracellular calcium pathways, the generation of reactive oxygen species (ROS), neurohormonal stress, and the induction of apoptosis. ${ }^{6}$ Zhifei et al. revealed that high-mobility group box 1 protein-mediated necroptosis contributes to dasatinib-induced cardiotoxicity. ${ }^{7}$

The incidence of cardiotoxicity was cited to be similar to that of the onset of heart failure in the general population, estimated at $0.2 \%$ per year, as evidenced by new-onset heart failure or left ventricular dysfunction. ${ }^{8}$ Ghias et al. reported a case of rapidly progressive dyspnea and heart failure in an elderly male with metastatic GIST, who received imatinib for just two weeks. ${ }^{9}$ However, imatinib-induced severe acute heart failure and fatal thrombocytopenia have not been reported in China.

Considering the aforementioned case summary and toxic cardiomyopathy pathogenesis, we presume that this complication in the patient may be due to the long-term use of imatinib and a myocardial structural defect. Thus, this case report raises awareness about the accelerated cardiotoxicity profile of imatinib. Further prospective studies with multidisciplinary input are needed to further establish this association.

Imatinib is generally a safe and effective drug; and most adverse reactions are mild and tolerable. Although myocardial damage is rare, it is still worthy of attention. The potential risk of heart disease should be evaluated before and during the use of imatinib, such as routine blood test, heart color Doppler ultrasound examination, and brain natriuretic peptide levels.

\section{FUNDING:}

This study was sponsored by the Science Foundation of Mianyang Center Hospital (2019FH04). 


\section{PATIENT'S CONSENT:}

Informed consent was obtained from the patient's family for publication of this case report and accompanying images.

\section{CONFLICT OF INTEREST:}

The authors declared no conflict of interest.

\section{AUTHORS' CONTRIBUTIONS:}

\section{ZL, WQ: Treated the patient.}

$X Z$, YL: Drafted the manuscript.

$\mathrm{XH}$, JW: Performed data retrieval; and statistical analysis; and helped draft the manuscript.

All authors read and approved the final manuscript for publication.

\section{REFERENCES}

1. Waller CF. Imatinib Mesylate. Recent Results Cancel Res 2018; 212:1-27. doi:10.1007/978-3-319-91439-8_1.

2. Francisco ARG, Alves D, David C, Guerra L, Pinto FJ, Almeida AG. Cardiotoxicity in hematological diseases: Are the tyrosine kinase inhibitors imatinib and nilotinib safe. Cardiovasc Toxicol 2018; 18(5):431-5. doi: 10.1007/ s12012-018-9453-3.

3. Savi M, Frati C, Cavalli S, Graiani G, Galati S, Buschini A, et al. Imatinib mesylate-induced cardiomyopathy involves resident cardiac progenitors. Pharmacol Res 2018; 127: 15-25. doi: 10.1016/j. phrs.2017.09.020.
4. Chambers TP, Santiesteban L, Gomez D, Chambers JW. Sab mediates mitochondrial dysfunction involved in imatinib mesylate-induced cardiotoxicity. Toxicol 2017; 382:24-35. doi: 10.1016/j.tox.2017.03.006.

5. Trent JC, Patel SS, Zhang J, Araujo DM, Plana JC, Lenihan DJ, et al. Rare incidence of congestive heart failure in gastrointestinal stromal tumor and other sarcoma patients receiving imatinib mesylate. Cancer 2010; 116(1):184-92. doi: 10.1002/cncr.24683.

6. Hantson P. Mechanisms of toxic cardiomyopathy. Clin Toxicol (Phila). 2019; 57(1):1-9. doi:10.1080/15563650. 2018.1497172.

7. Zhifei X, Ying J, Hao Y, Gao Z, Xu B, Yang B, et al. Highmobility group box 1 protein-mediated necroptosis contributes to dasatinib-induced cardiotoxicity. Toxicol Lett 2018; 296:39-47. doi: 10.1016/j.toxlet.2018.08.003.

8. Kim KW, Shinagare AB, Krajewski KM, Pyo J, Tirumani SH, Jagannathan JP, et al. Fluid retention associated with imatinib treatment in patients with gastrointestinal stromal tumor: Quantitative radiologic assessment and implications for management. Korean J Radiol 2015; 16(2):304-13. doi: 10.3348/kjr.2015.16.2.304.

9. Ghias AAP, Bhayani S, Gemmel DJ, Garg SK. Rapidly progressive dyspnea in gastrointestinal stromal tumor (GIST) with imatinib cardiac toxicity. J Community Hospital Intern Med Perspectives 2018; 8(2):87-91. doi: 10.1080/ 20009666.2018.1454787. 